\title{
Microbial habitat connectivity across spatial scales and hydrothermal temperature gradients at Guaymas Basin
}

\author{
Stefanie Meyer ${ }^{1,2}$, Gunter Wegener ${ }^{1,2,3}$, Karen G. Lloyd ${ }^{4}$, Andreas Teske ${ }^{5}$, Antje Boetius ${ }^{1,2}$ and \\ Alban Ramette ${ }^{1,2 *}$ \\ ${ }^{1}$ HGF-MPG Joint Research Group on Deep Sea Ecology and Technology, Alfred Wegener Institute for Polar and Marine Research, Bremerhaven, Germany \\ 2 HGF-MPG Joint Research Group on Deep Sea Ecology and Technology, Max Planck Institute for Marine Microbiology, Bremen, Germany \\ ${ }^{3}$ MARUM Center for Marine Environmental Sciences, University of Bremen, Bremen, Germany \\ ${ }^{4}$ Department of Microbiology, University of Tennessee, Knoxville, TN, USA \\ ${ }^{5}$ Department of Marine Sciences, University of North Carolina - Chapel Hill, Chapel Hill, NC, USA
}

Edited by:

Anna-Louise Reysenbach, Portland

State University, USA

Reviewed by:

Barbara J. Campbell, Clemson

University, USA

William D. Orsi, Woods Hole

Oceanographic Institution, USA

\section{*Correspondence:}

Alban Ramette, HGF-MPG Joint

Research Group, Max Planck

Institute for Marine Microbiology,

Celsiusstr. 1, 28359 Bremen,

Germany

e-mail:aramette@mpi-bremen.de
The Guaymas Basin (Gulf of California) hydrothermal vent area is known as a dynamic and hydrothermally vented sedimentary system, where the advection and production of a variety of different metabolic substrates support a high microbial diversity and activity in the seafloor. The main objective of our study was to explore the role of temperature and other environmental factors on community diversity, such as the presence of microbial mats and seafloor bathymetry within one hydrothermally vented field of $200 \times 250 \mathrm{~m}$ dimension. In this field, temperature increased strongly with sediment depth reaching the known limit of life within a few decimeters. Potential sulfate reduction rate as a key community activity parameter was strongly affected by in situ temperature and sediment depth, declining from high rates of $1-5 \mu \mathrm{mol} \mathrm{ml}^{-1} \mathrm{~d}^{-1}$ at the surface to the detection limit below $5 \mathrm{~cm}$ sediment depth, despite the presence of sulfate and hydrocarbons. Automated Ribosomal Intergenic Spacer Analysis yielded a high-resolution fingerprint of the dominant members of the bacterial community. Our analyses showed strong temperature and sediment depth effects on bacterial cell abundance and Operational Taxonomic Units (OTUs) number, both declining by more than one order of magnitude below the top $5 \mathrm{~cm}$ of the sediment surface. Another fraction of the variation in diversity and community structure was explained by differences in the local bathymetry and spatial position within the vent field. Nevertheless, more than $80 \%$ of all detected OTUs were shared among the different temperature realms and sediment depths, after being classified as cold $\left(T<10^{\circ} \mathrm{C}\right)$, medium $\left(10^{\circ} \mathrm{C} \leq T<40^{\circ} \mathrm{C}\right)$ or hot $\left(T \geq 40^{\circ} \mathrm{C}\right)$ temperature conditions, with significant OTU overlap with the richer surface communities. Overall, this indicates a high connectivity of benthic bacterial habitats in this dynamic and heterogeneous marine ecosystem influenced by strong hydrothermalism.

Keywords: microbial habitat connectivity, bacterial diversity, Guaymas Basin, ARISA

\section{INTRODUCTION}

The Guaymas Basin is located in the central Gulf of California and represents a unique hydrothermal sedimentary basin. Hightemperature fluids, which pass through an on average $100-\mathrm{m}$ thick sedimentary cover, facilitate the pyrolysis of buried organic matter (Simoneit and Lonsdale, 1982) and enrich hydrothermal sediments in petroleum-like compounds, light hydrocarbons (methane, organic acids) and ammonia (Von Damm et al., 1985; Bazylinski et al., 1988; Martens, 1990). The hydrothermal sediments are characterized by a wide range in temperature regimes, generally reaching the known limits of life $\left(>120^{\circ} \mathrm{C}\right)$ at $15-40 \mathrm{~cm}$ below the sediment surface (McKay et al., 2012). The fluids discharged at Guaymas Basin contain hydrogen, carbon dioxide and hydrogen sulfide (Welhan and Lupton, 1987; Elsgaard et al., 1994; Paull et al., 2007). Supported by this large variety of potential microbial energy sources, Guaymas Basin sediments host diverse anaerobic and aerobic microbial communities (Teske et al., 2002). Among these are the giant sulfide oxidizers Beggiatoa that can form thick white and orange bacterial mats on the seafloor, in habitats characterized by high sulfide fluxes (Jannasch et al., 1989; Nelson et al., 1989; McKay et al., 2012). In benthic ecosystems, these mats are hence often used as visual indicators of biogeochemical hotspots of high hydrocarbon flux and chemosynthetic production (Van Gaever et al., 2006; Lichtschlag et al., 2010; Lloyd et al., 2010). The key microbial processes such as nitrification (Mével et al., 1996; Baker et al., 2012), nitrate reduction (Bowles et al., 2012), sulfate reduction (Elsgaard et al., 1994; Weber and Jørgensen, 2002; Dhillon et al., 2003) and methanogenesis (Dhillon et al., 2005; Teske, 2010), were found to occur across a wide range of temperatures, suggesting a high diversity of the main functional groups of bacteria and archaea. Archaeal-bacterial consortia that mediate the anaerobic oxidation of methane (AOM) with sulfate are an important microbial community component in the Guaymas hydrothermal sediments (Teske et al., 2002, 2003), but ex-situ measurements of AOM have shown that this process is limited to temperatures $<80^{\circ} \mathrm{C}$ 
(Kallmeyer and Boetius, 2004). Previous studies indicated that different types of methanotrophs are favored by different temperature ranges (Holler et al., 2011; Biddle et al., 2012).

Few studies have investigated in detail spatial distribution patterns of microbial communities at Guaymas Basin (e.g., Guezennec et al., 1996; Edgcomb et al., 2002; Kysela et al., 2005), to understand the main drivers of microbial diversity. Microbes are known to display biogeographic patterns, ranging from cosmopolitanism to provincialism, but the underlying mechanisms that generate and maintain those patterns at a wide range of spatial scales remain largely underexplored (Hughes Martiny et al., 2006; Ramette and Tiedje, 2007a; Zinger et al., 2011; Hanson et al., 2012). Within the conceptual framework of metacommunity dynamics (Leibold et al., 2004), and by statistically disentangling the effects of space and environment on community composition, insights into community assembly mechanisms such as patch dynamics, species sorting, mass effects or neutral processes, or combination thereof, may be obtained and quantified (Cottenie, 2005).

In this study, a high-resolution sampling effort of hydrothermal sediments was conducted, investigating the patchiness of bacterial communities at spatial scales ranging from decimeters to hundreds of meters, and across temperature ranges typical for psychrophilic $\left(T<10^{\circ} \mathrm{C}\right)$, mesophilic $\left(10^{\circ} \mathrm{C} \leq T<40^{\circ} \mathrm{C}\right)$ and thermophilic $\left(T \geq 40^{\circ} \mathrm{C}\right)$ communities. Community fingerprinting data were obtained by Automated Ribosomal Intergenic Spacer Analysis (ARISA), which is useful to describe variations in bacterial community structure at a higher genetic resolution than what is provided by $16 \mathrm{~S}$ rRNA gene sequencing (e.g., Brown et al., 2005; Nocker et al., 2007), because it is based on the amplification of the more variable ITS (Internal Transcribed Spacer) region. It may thus help reveal core communities and community shifts of the dominant bacterial types (Nocker et al., 2007; Fuhrman et al., 2008), but see Ramette (2009) for the possible detection of minor populations. To test for a potential effect of niche differentiation by temperature regimes on Guaymas Basin benthic bacterial communities, the following variables were chosen: in situ temperature was assessed during sampling, and vertical profiles of microbial assemblages inhabiting different temperature ranges were compared. Spatial variation was additionally assessed by latitude, longitude and water depth, relating to seafloor landscape features such as hydrothermal mounds. Further environmental parameters included bacterial mat presence/color as potential indicators for habitat heterogeneity, e.g., with regard to sulfide fluxes (Grünke et al., 2012; McKay et al., 2012). To infer potential changes in microbial abundance and function, microbial cell numbers, and potential sulfate reduction rates were included as additional parameters.

\section{MATERIALS AND METHODS SAMPLE COLLECTION}

Sediment samples were obtained from a hydrothermally active field of $0.05 \mathrm{~km}^{2}$ in the Southern Guaymas trench (Gulf of California, $\sim 2000 \mathrm{~m}$ water depth, $27^{\circ} 00.37^{\prime} \mathrm{N}$ to $27^{\circ} 00.49^{\prime} \mathrm{N}$ and $111^{\circ} 24.58^{\prime} \mathrm{W}$ to $111^{\circ} 24.44^{\prime} \mathrm{W}$ ), by push coring into enclosed plastic tubes with the Alvin submersible (operated by Woods Hole Oceanographic Institution, Woods Hole, MA) during R/V
Atlantis expedition AT15-40 in December 2008. In situ subsurface temperatures were measured before coring $(<50 \mathrm{~cm}$ away from the sampled areas) by using either the external "High Temperature Probe" or the external "Heatflow Probe" on the Alvin submersible (operated by WHOI; for probe details see McKay et al., 2012). The temperature values used in this study are reported in Table S1. Replicate sediment cores were collected separately for bacterial community analyses, for sulfate reduction rate measurements and for pore water geochemistry. During ascent of the submersible, all cores were tightly closed and stored upright in a fixed position. Cores with intact layering of mats and sediments were used for further analyses. Subsampling of the cores occurred within $4-12 \mathrm{~h}$ after sampling and storage at $4^{\circ} \mathrm{C}$. The upper $10-30 \mathrm{~cm}$ of sediment cores were sectioned into $1-\mathrm{cm}$ and $2-\mathrm{cm}$ horizons and were preserved for subsequent analyses accordingly (see below). Samples for molecular work were immediately frozen at $-20^{\circ} \mathrm{C}$.

\section{DETERMINATION OF SULFATE CONCENTRATIONS AND SULFATE REDUCTION RATES}

For a limited number of cores, pore water was extracted by centrifugation of sediment from the respective horizons, and sulfate pore water concentrations were measured as described previously (Biddle et al., 2012; McKay et al., 2012). Additional cores were used to measure sulfate turnover constants ex situ using the whole-core injection method (Jørgensen, 1978) with 5-10 $\mu 1$ carrier-free ${ }^{35} \mathrm{SO}_{4}^{2-}$ (dissolved in water, $50 \mathrm{kBq}$ ) in the dark, at a fixed temperature of $20^{\circ} \mathrm{C}$ for all cores. After $8-24 \mathrm{~h}$ incubation time, samples were preserved in $20 \mathrm{ml}$ of $20 \%$ (w/v) ZnAc solution. Sulfate turnover constants (Table S2) and average sulfate concentrations (Table S3) determined in adjacent cores of the same dive were used to calculate potential sulfate reduction rates (Kallmeyer et al., 2004; Felden et al., 2010). Because of the substantial heterogeneity of in situ temperature and pore water composition between cores a few centimeters or decimeters apart (McKay et al., 2012), the resulting potential sulfate reduction rates (Table S2) should be regarded as an approximation. To show that sulfate concentrations are variable even over small spatial scales, the measured sulfate turnover constants are plotted alongside sulfate concentrations for nearby cores in Figure S1.

\section{ACRIDINE ORANGE DIRECT CELL COUNTING (AODC)}

Sediment sections $(2 \mathrm{ml})$ for microbial cell counts were fixed onboard in $4 \%$ formaldehyde/seawater $(9 \mathrm{ml})$ and stored at $4{ }^{\circ} \mathrm{C}$. In the home laboratories, samples were stained with acridine orange according to a modified protocol (Boetius and Lochte, 1996) of Meyer-Reil (1983). For each sample, single cells were counted on at least 2 replicate filters and for a minimum of 30 random grids per filter (dilution factors 2000-4000).

\section{BACTERIAL COMMUNITY FINGERPRINTING}

Sediment sections for DNA analyses were directly transferred to sterile plastic tubes and were kept frozen at $-20^{\circ} \mathrm{C}$ until further use in the home laboratories. Total community DNA was extracted from $1 \mathrm{~g}$ of sediment by using the Ultra Clean Soil DNA Isolation Kit (MoBio, Carlsbad, CA) and by following the manufacturer's specifications for maximum yield. DNA was 
eluted in $100 \mu \mathrm{l} 1 \times$ TE buffer (Promega Corporation, Madison, WI) and stored at $-20^{\circ} \mathrm{C}$ until further use. DNA concentration per volume buffer was measured by using a NanoQuant infinite M200 (Tecan, Crailsheim, Germany). Bacterial community analyses are based on profiles generated by Automated Ribosomal Intergenic Spacer Analysis (ARISA). The procedure has been previously published in detail (Ramette, 2009). In this study, a slightly modified version of the protocol was used: Within a $50 \mu \mathrm{l}$ reaction, final concentrations of PCR ingredients were $0.4 \mu \mathrm{M}$ of each primer (Biomers, Ulm, Germany), $250 \mu \mathrm{M}$ of each dNTP (peqGOLD Kit; Peqlab, Erlangen, Germany), $0.1 \mathrm{mg} \mathrm{ml}^{-1}$ BSA (Sigma-Aldrich Biochemie GmbH, Hamburg, Germany), $1 \times$ Buffer $\mathrm{S}$ with $1.5 \mathrm{mM} \mathrm{MgCl}_{2}$ (Peqlab), $1.0 \mathrm{mM}$ extra $\mathrm{MgCl}_{2}$ (Peqlab) and $2.5 \mathrm{U}$ peqGOLD Taq-DNA-Polymerase (Peqlab). Per reaction, 20-25 ng of extracted DNA were used as template. Primers were ITSF (FAM-5'-GTC GTA ACA AGG TAG CCG TA$3^{\prime}$ Cardinale et al., 2004) and ITSReub (5'-GCC AAG GCA TCC ACC-3' Cardinale et al., 2004).

\section{STATISTICAL ANALYSES}

Quality assessment of ARISA profiles and binning were done as described in Ramette (2009). For merging PCR replicate profiles into master profiles, Operational Taxonomic Units (OTUs) consisted of peaks that occurred at least once among the respective PCR triplicates. All numerical analyses were conducted in R (v.2.13.2; The R Foundation for Statistical Computing; www.R-project.org) using the vegan library as well as standard packages and custom scripts (available at www.ecologyresearch.com).

Contextual parameters are summarized in Tables S1 and S4. DNA concentrations and total cell numbers were log-transformed to ensure normal distribution of the data. Presence and absence of mat as well as mat color (i.e., white, orange and yellow vs. no mat) were recoded as dummy variables (Ramette, 2007). Numbers of shared OTUs between different categories of contextual parameters were calculated by first merging all respective profiles of a given category into a single community profile where all peaks present were counted. Non-metric Multidimensional Scaling (NMDS) was used to represent dissimilarity matrices based on Bray-Curtis or Jaccard coefficients into a reduced space (Legendre and Legendre, 1998). Redundancy Analysis (RDA) models were combined with stepwise selection procedure, so as to retain the minimum number of significant variables as indicated by minimal Akaike Information Criterion (AIC) model value. Different sets of explanatory variables were then tested for significance in a variation partitioning framework (Borcard et al., 1992; Ramette, 2007). When negative $R^{2}$ values were obtained, as it is the case sometimes for partial regression models (Legendre and Legendre, 1998), they were set to 0, and the total explained variation was recalculated, by adding up only the positive fractions. The heterogeneity of bacterial community structures among and between samples associated to certain environmental categories was quantified by their average variation in bacterial beta-diversity to each category's centroid (e.g., Zinger et al., 2011) and tested for significance by ANOVA followed by Tukey's Honestly Significant Difference tests, as implemented in the R package vegan.

\section{RESULTS \\ SITE DESCRIPTION}

To gain insight into the processes generating and maintaining bacterial community structure at Guaymas Basin, 21 sediment cores were obtained across an area of $200 \times 250 \mathrm{~m}$, including more or less hydrothermally vented sediments, and one background core was retrieved from outside the vent field (Figure 1; Table 1). The sampling area was located within a hilly area of the Southern Guaymas trench (Gulf of California) covering water depths of 1995-2013 m, and harboring hydrothermal mounds densely populated by Riftia tubeworms, sulfide spires and flanges as well as numerous white, orange and yellow Beggiatoa mats on the seafloor, some of them growing on mounds. One of these mounds, termed "Mat Mound" (N2700.388; W111²4.560) was surrounded by an apron of hydrothermally active sediments overgrown with microbial mats, and was repeatedly visited for sampling (Figures 2A,B). Sediment pushcores aPC7, aPC12 and aPC6 (Figure 1) and several sulfate reduction cores (Figure S1) were sampled at this location. Bacterial mats growing on sediment surfaces typically had diameters of 1-2 $\mathrm{m}$ and could be several $\mathrm{cm}$ thick. One large mat-covered hydrothermal sediment area termed

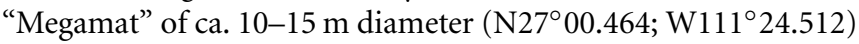
was visited and sampled repeatedly (Figures 2C,D); the subsurface temperature field underlying a portion of this extensive hydrothermal area was mapped and reconstructed in 3D (McKay et al., 2012). Pushcores PC18, PC23, PC24, and aPC35 (Figure 1) and several sulfate reduction cores (Figure S1) were sampled on the edge of Megamat. A smaller, orange-colored microbial mat termed $\mathrm{UNC}$ Mat $\left(\mathrm{N} 27^{\circ} 00.445\right.$, W111 24.530$)$ ca. $20 \mathrm{~m}$ southwest of Megamat was sampled (Figures 2E,F). This location showed strong in situ evidence for high-temperature sulfatedependent methane oxidation (Biddle et al., 2012). Here sediment core bPC12 (Figure 1) and several sulfate reduction cores (Figure S1) were sampled. Additional sampling sites were visited, several of them on extensive survey dives (Alvin dives 4492 and 4493) to maximize the geographic range of sediment cores (Figure 1, Table 1).

The distribution of mats across the overall investigated sampling area was patchy, and there was no obvious spatial gradient in the temperature field or in the distribution of bacterial mats recorded. As Beggiatoa mats are known to indicate geochemical and biodiversity hotspots (Lloyd et al., 2010; Grünke et al., 2012; McKay et al., 2012), they were repeatedly sampled within this study, resulting in the recovery of 13 mat-covered cores and 8 mat-free cores for comparison. Upon recovery, most cores were found to be rich in methane gas (Biddle et al., 2012; McKay et al., 2012). In situ subsurface temperatures varied between 3 and $96^{\circ} \mathrm{C}$ in the upper $10 \mathrm{~cm}$ of sediment (Table S1), and cores were classified into different temperature ranges according to these measurements.

Potential microbial sulfate reduction rates assessed at $20^{\circ} \mathrm{C}$ reached values as high as $5500 \mathrm{nmol} \mathrm{ml}^{-1} \mathrm{~d}^{-1}$ in the surface layers originating from an in situ temperature range of $3-40^{\circ} \mathrm{C}$ (Table S2), but then decreased abruptly beneath $5 \mathrm{~cm}$ sediment depth (in situ T approx. $10-40^{\circ} \mathrm{C}$ ), and were almost absent below $10 \mathrm{~cm}$ (in situ $T$ range $20-96^{\circ} \mathrm{C}$ ) (Figure 3A, Table S1). In most cores sulfate was not depleted within the top $10 \mathrm{~cm}$, indicating 


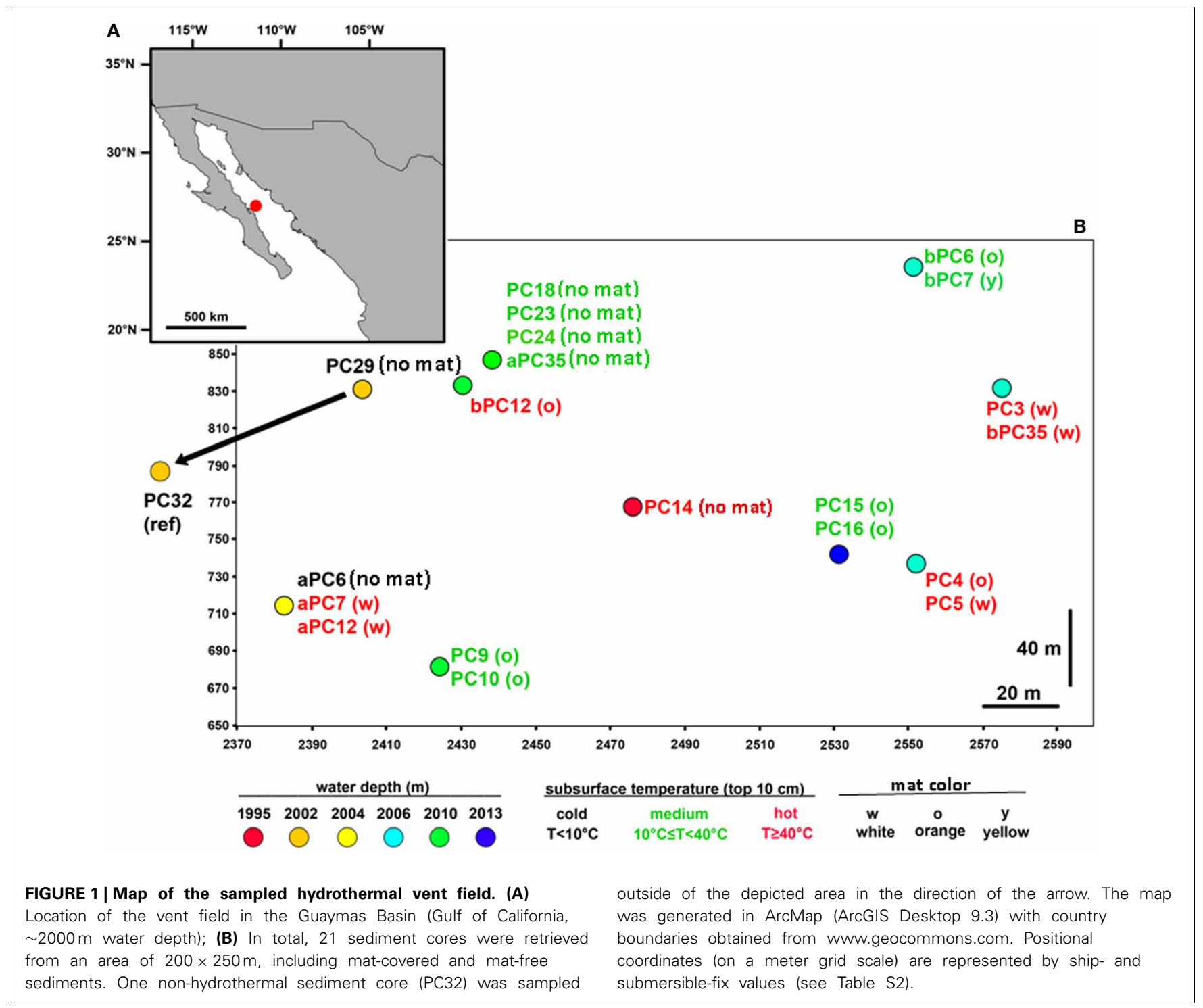

that availability of electron donors or sulfate did not limit sulfate reduction (Figure 3B; Table S3). This observed predominance of mesophilic sulfate reduction in surficial sediment layers may partially be explained by the fact that all potential sulfate reduction rate measurements were conducted at $20^{\circ} \mathrm{C}$; thus, the contribution of high-temperature sulfate reduction rates to overall sedimentary sulfate-reducing activity was not assessed in this study. However, cell numbers also decreased rapidly with increasing sediment depth (Figure 3C; Table S4), varying between 1.0 and $3.7 \times 10^{9}$ cells ml $^{-1}$ in mat-covered and mat-free surface sediments, and declining to $<0.6 \times 10^{9} \mathrm{cells} \mathrm{ml}^{-1}$ in sediment layers below $5 \mathrm{~cm}$.

\section{EVALUATION OF ENVIRONMENTAL FACTORS AFFECTING COMMUNITY STRUCTURE AND FUNCTION}

Indicator factors for habitat variation tested within this study included in situ seafloor temperature $(\mathrm{T})$, mat color/presence (MC) and sediment depth (SD), as well as bathymetry (measured as water depth, $\mathrm{WD})$, and coordinates in the local sampling grid in meters $(\mathrm{X}, \mathrm{Y})$ as defined by seafloor radiobeacons (pingers) set out by RV Atlantis before the start of the sampling campaign (Table S4). Linear (Pearson) and rank-based (Spearman) correlations were used to determine the degree of correlation between all numerical parameters for the most complete subset of the data, which included $T$ (real temperature values with number of samples $n=46$; Table S1), SD, WD, X and Y. The analyses revealed significant positive correlations between SD and $T$ (Pearson's $r=$ $0.653, P<0.001)$, with the deeper sediment layers representing hotter habitats (Table S1), as well as between $\mathrm{X}$ and $\mathrm{Y}$ sampling grid coordinates (Pearson's $r=0.420, P<0.01$ ), reflecting the fact that most of the sampling took place within a specific area, and not randomly dispersed around the zero origin of the coordinates. All other pairwise comparisons among parameters (i.e., $\mathrm{T}, \mathrm{SD}, \mathrm{WD}, \mathrm{X}$ and $\mathrm{Y}$ ) were not significant. Mat color variation was found to be significantly related to bathymetry (WD; F ratio $=11.003, P \leq 0.001$; explaining $20 \%$ of the variation in 
Table 1 | Cores analyzed in this study by ARISA.

\begin{tabular}{|c|c|c|c|c|c|}
\hline Label & Date & Dive & $\begin{array}{l}\text { Water } \\
\text { depth (m) }\end{array}$ & Location & Core description \\
\hline aPC12 & 06.12 .08 & 4483 & 2004 & Mat mound & Gray sediment with dark green and brown spots in between; white mat \\
\hline aPC7 & 07.12 .08 & 4484 & 2004 & Mat mound & Gray sediment; white mat \\
\hline aPC6 & 09.12 .08 & 4485 & 2004 & Outside mat mound & Green-gray sediment, worms; no mat \\
\hline PC23 & 10.12 .08 & 4486 & 2010 & Outside Megamat & Olive-green sediment, gas holes; no mat \\
\hline PC18 & 10.12 .08 & 4486 & 2010 & Outside Megamat & Top $5 \mathrm{~cm}$ fluffy brown, then olive-green sediment, gas holes; no mat \\
\hline PC24 & 10.12 .08 & 4486 & 2010 & Outside Megamat & Top dark olive-green, rest olive-green, worm carcasses; no mat \\
\hline bPC12 & 14.12 .08 & 4489 & 2010 & UNC mat, near Megamat & $\begin{array}{l}\text { Top } 5 \mathrm{~cm} \text { fluffy, then olive sediment, hole at bottom, sulfidic; orange mat with } \\
\text { few white filaments }\end{array}$ \\
\hline aPC35 & 15.12 .08 & 4490 & 2010 & Megamat & Top 9-10 cm blackish, then olive-gray, gas holes, oily spots; no mat \\
\hline PC32 & 16.12 .08 & 4491 & 2002 & 100 m from Megamat & $\begin{array}{l}\text { Top 1-3 cm fluffy blackish sediment, then mixed dark-gray with green-brown } \\
\text { sediment; no detectable hydrothermal temperature gradient; no mat }\end{array}$ \\
\hline PC29 & 16.12 .08 & 4491 & 2002 & $50 \mathrm{~m}$ from Megamat & $\begin{array}{l}\text { Top 1-3 cm fluffy brown sediment, then olive-gray sediment; no detectable } \\
\text { hydrothermal temperature gradient; no mat }\end{array}$ \\
\hline PC3 & 17.12 .08 & 4492 & 2006 & Survey site 1 & $\begin{array}{l}\text { Bubbling, top } 2-4 \mathrm{~cm} \text { brownish fluffy, then oily layer with oil/gas pockets, then } \\
\text { grayish sediment, worm; white mat }\end{array}$ \\
\hline PC4 & 17.12 .08 & 4492 & 2006 & Survey site 2 & $\begin{array}{l}\text { Bubbling, } 9 \mathrm{~cm} \text { organic layer, oily, with gas/oil pockets, then grayish sediment; } \\
\text { orange mat }\end{array}$ \\
\hline bPC6 & 17.12 .08 & 4492 & 2006 & Survey site 3 & $\begin{array}{l}\text { Top } 2 \mathrm{~cm} \text { fluffy, then } 5 \mathrm{~cm} \text { blackish, then olive sediment; orange mat with } \\
\text { yellow parts }\end{array}$ \\
\hline bPC35 & 17.12 .08 & 4492 & 2006 & Survey site 1 & $\begin{array}{l}\text { Fluffy brownish layer (partly pushed to bottom of the core), then grayish } \\
\text { sediment with darker spots in-between, core liner melted at the bottom; } \\
\text { white mat }\end{array}$ \\
\hline PC5 & 17.12 .08 & 4492 & 2006 & Survey site 2 & $\begin{array}{l}\text { Bubbling, } 1 \mathrm{~cm} \text { gray sediment on top, then } 4 \mathrm{~cm} \text { grayish-brownish fluff, then } \\
4 \mathrm{~cm} \text { olive and oily layer with gas/oil pockets, then grayish sediment (more } \\
\text { compact); white mat }\end{array}$ \\
\hline bPC7 & 17.12 .08 & 4492 & 2006 & Survey site 3 & Top $4 \mathrm{~cm}$ fluffy, then $4.5 \mathrm{~cm}$ darker and then brown-olive sediment; yellow mat \\
\hline PC9 & 18.12 .08 & 4493 & 2010 & Survey site 4 & $\begin{array}{l}8 \mathrm{~cm} \text { grayish sediment, then mixed layer with red oily droplets, white } \\
\text { inclusions towards the bottom; orange mat }\end{array}$ \\
\hline PC10 & 18.12 .08 & 4493 & 2010 & Survey site 4 & $\begin{array}{l}4 \mathrm{~cm} \text { fluffy, then mixed sediment, some white inclusions, holes, red oily } \\
\text { droplets; orange mat }\end{array}$ \\
\hline PC14 & 18.12 .08 & 4493 & 1995 & Survey site 5 & Top $6 \mathrm{~cm}$ darker, then $12 \mathrm{~cm}$ greenish, then $8 \mathrm{~cm}$ grayish sediment; no mat \\
\hline PC15 & 18.12 .08 & 4493 & 2013 & Survey site 6 & Olive sediment with blackish spots at top; orange mat \\
\hline PC16 & 18.12 .08 & 4493 & 2013 & Survey site 6 & $3 \mathrm{~cm}$ fluffy, then olive-grayish sediment, white deposits, holes; orange mat \\
\hline
\end{tabular}

mat color) and spatial distance $(\mathrm{X}+\mathrm{Y} ; \mathrm{F}$ ratio $=8.135, P \leq$ $0.001 ; 25 \%$ of explained variation). There was no significant relationship between $\mathrm{MC}$ and $\mathrm{T}$, when using the subset of data for which contextual in situ temperatures were obtained $(n=46)$. However, when assigning the full data set including all sediment depths $(n=188)$ into three temperature categories (cold $T<$ $10^{\circ} \mathrm{C}$, medium $10^{\circ} \mathrm{C} \leq T<40^{\circ} \mathrm{C}$, hot $T \geq 40^{\circ} \mathrm{C}$, as measured in the upper $10 \mathrm{~cm}$ of sediment), $T$ was significantly $(P \leq 0.001)$ related to $\mathrm{MC}$ and explained up to $28 \%$ of the observed variation. Within individual mat locations, orange mats were found in the central area (Figure 1) characterized by the steepest geochemical gradients, and inferred hydrothermal fluxes (McKay et al., 2012), and were associated with temperatures ranging from 4 to $96^{\circ} \mathrm{C}$ (average $33 \pm 26.5[\mathrm{sd}]{ }^{\circ} \mathrm{C}$; Table S4).

\section{MICROBIAL CELL NUMBERS AND VARIATION IN OTU NUMBER}

Cell numbers declined significantly with sediment depth (partial coefficient $=-0.161, P<0.001)$. The overall variation in cell numbers (Figure 4A) was significantly explained by SD and WD (full model: $74 \%$; $n=49$ ), with SD alone explaining up to $66 \%$ of the observed variation $(P<0.001)$, while WD, respectively, explained $0.5 \%(P<0.01$; partial coefficient $=0.144, P<$ 0.001 ) of the variation in cell number (see Supplementary text and Figure S2, for analyses of the variation in extracted DNA concentrations).

Furthermore, also OTU number decreased with increasing temperature and sediment depth (Figure 3D). A total pool of 439 different OTUs was detected when considering all 188 samples, with OTU numbers per sample ranging from 1 to 223 . OTU numbers were negatively related with SD (Figures S3, S4; Pearson's $r=$ $-0.567, P<0.001 ; n=188$ ) and $T$ (Pearson's $r=-0.500, P<$ $0.001 ; n=46$, real temperature values), representing a substantial loss of bacterial richness with deeper, generally hotter sediments. Higher OTU numbers were obtained on average for the upper sediment layers $(112 \pm 65$ OTUs; $0-10.5 \mathrm{~cm})$ than for the deeper ones ( $54 \pm 61$ OTUs; $11-24 \mathrm{~cm}$ ). However, considering sediment 


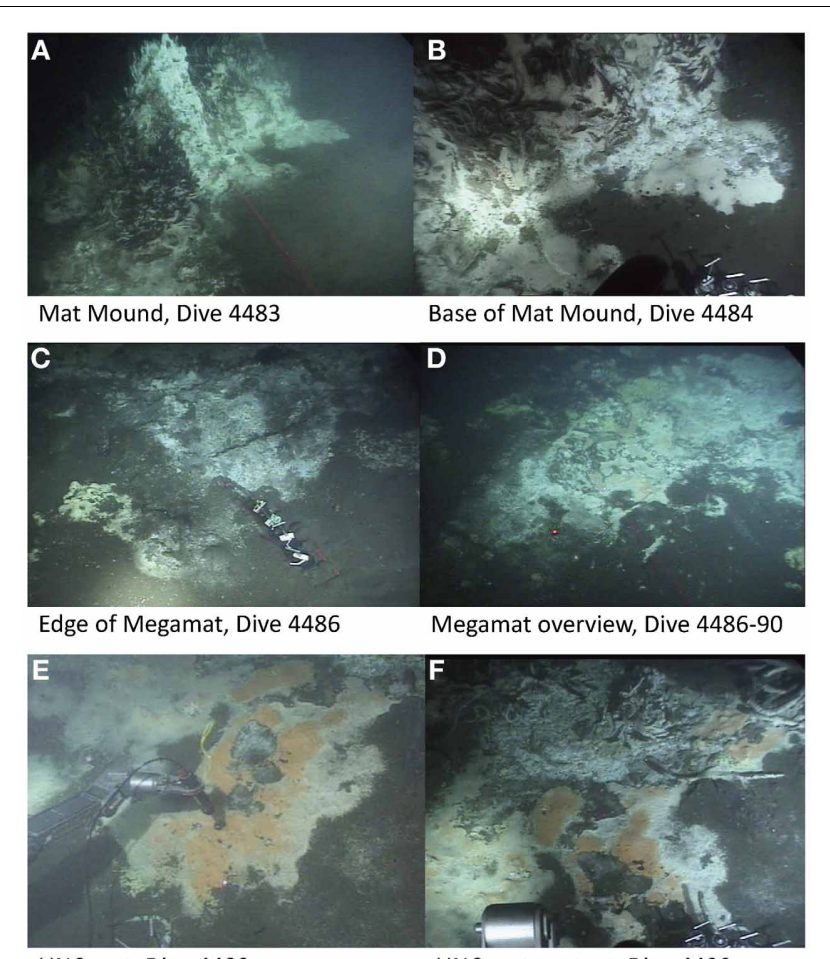

UNC mat, Dive 4489

UNC mat context, Dive 4490

FIGURE 2 | Selected sampling sites of the Southern Guaymas trench. This area is characterized by the occurrence of Riftia around hydrothermal mounds such as Mat Mound (A,B) and dense bacterial mats of white, orange or yellow color that are mainly formed by the giant sulfide oxidizer Beggiatoa on the sediment surface, for example at Megamat (C,D) and the UNC mat (E,F). Image source: Woods Hole Oceanographic Institution, Woods Hole, MA.

depth alone, maximum and minimum numbers of OTUs fell into a wide range, with 3-223 OTUs for the upper horizons and 1-218 OTUs for the deeper layers. The two depth categories had $90 \%$ OTUs in common.

Across all sediment depths, the range of OTU numbers determined for the different $T$ categories (cold $T<10^{\circ} \mathrm{C}$, medium $10^{\circ} \mathrm{C} \leq T<40^{\circ} \mathrm{C}$, hot $T \geq 40^{\circ} \mathrm{C}$ ) also varied widely, i.e., 30-223 OTUs (cold), 2-214 OTUs (medium) and 1-198 OTUs (hot), indicating a large spatial variability as well as potentially also a temporal variability of temperature (Figure 3D). The average OTU numbers decreased from cold to hot samples with $165 \pm 60$, $116 \pm 59$, and $90 \pm 63$ OTUs for cold, medium and hot samples, respectively. Cold and medium temperature samples shared $85 \%$, cold and hot samples $86 \%$, and medium and hot cores $90 \%$ of their OTUs (0-24 cm sediment depth). The reference core (PC32, cold), taken outside of the hydrothermal vent field, shared between 70 and $77 \%$ of its OTUs with any other cores taken within the surveyed area, while the percentages of shared OTUs was higher among samples within the vent field ranging from 83 and $90 \%$ (all $T$ categories compared). Further OTU partitioning revealed that the number of unique OTUs in cold (3 OTUs) and hot habitats (4 OTUs) was lower than that of intermediate temperatures (18 OTUs) (Figure 4B).
Mat presence was generally associated with lower OTU numbers for the upper $10 \mathrm{~cm}$ of sediment, with average values of $93 \pm 58$ for mat-covered sediments vs. $149 \pm 61$ OTUs for matfree sites (see also Figure S5), concurring with previous work suggesting that the sulfide- and methane-rich regime selects for a more specialized microbial community than in normal surface sediments (Lloyd et al., 2010). However, when taking all sediment depths into account, no clear difference in total OTU numbers between mat-covered (2-198 OTUs) and mat-free sites (1-223 OTUs) could be detected. The percentage of shared OTUs between mat-free and mat-covered sediments ranged from 63 to $88 \%$. Multivariate analyses with the full data set $(n=188)$ indicated that variation in OTU number could be best explained by variation in $\mathrm{SD}(32 \%)$, space $(\mathrm{X}+\mathrm{Y} ; 7 \%)$ and $T(4 \%)$, altogether explaining $52 \%$ of the total variation (Figure $4 \mathrm{~A}$ ).

\section{CHANGES IN BACTERIAL COMMUNITY STRUCTURE}

When considering all samples on the NMDS ordination plot (Figure 5) a clear separation appeared between samples that contained $<70$ OTUs and those with a higher richness (as determined by a frequency distribution analysis; Figure S6). Overall, samples with OTU numbers $<70$ OTUs were less similar to each other (i.e., communities were more heterogeneous) than the ones with OTU numbers higher than 70 OTUs (Figure 5A). They were mostly associated with sediment layers deeper than $10 \mathrm{~cm}$ and a temperature range of $20-96^{\circ} \mathrm{C}$, depending on core and sampling location (Figure 5B; Table S1). Samples with OTU numbers $\geq 70$ OTUs were mostly associated to cold (19 samples, i.e., $18 \%$ of all samples) or medium temperature (73 samples or $70 \%$ ) conditions and generally originated from the top $10 \mathrm{~cm}$ surface layers (81 samples, i.e., 77\% of all samples) (Figure 5C; Figure S7). No significant pattern was found to be associated with variation in mat color (Figure 5D), but within the group of samples with $\geq 70$ OTUs, mat-free sediment samples were more similar to each other than mat-associated ones (Figure 5D).

When taking all contextual parameters analyzed here into account, $24 \%$ of the observed variation in bacterial community structure could be explained (Figure 4A; $n=188$ ). Most of the variation was explained by SD (7\%) and MC (4\%), followed by spatial distance $(\mathrm{X}+\mathrm{Y}, 3 \%), T(2 \%)$ and WD (2\%), when taking the variations of each other parameter into account (partial regression analyses done via variation partitioning). All of these factors had highly significant $(P \leq 0.001)$ effects. Beta dispersion analyses revealed that medium temperature cores contained the highest community heterogeneity (average distance to centroid: 0.60 ), as compared to hot (average distance to centroid: 0.58), and cold cores (average distance to centroid: 0.46 ). Tukey's HSD tests indicated highly significant differences between cold cores and all other categories $(P<0.001)$, but no significant difference between hot and medium cores $(P>0.05)$.

\section{DISCUSSION}

\section{IMPACT OF TEMPERATURE ON BENTHIC BACTERIAL COMMUNITIES AT GUAYMAS BASIN}

Guaymas Basin hydrothermal sediments are rich in hydrocarbons, methane, hydrogen sulfide, and contain a variety of other potential microbial energy sources, supporting complex 


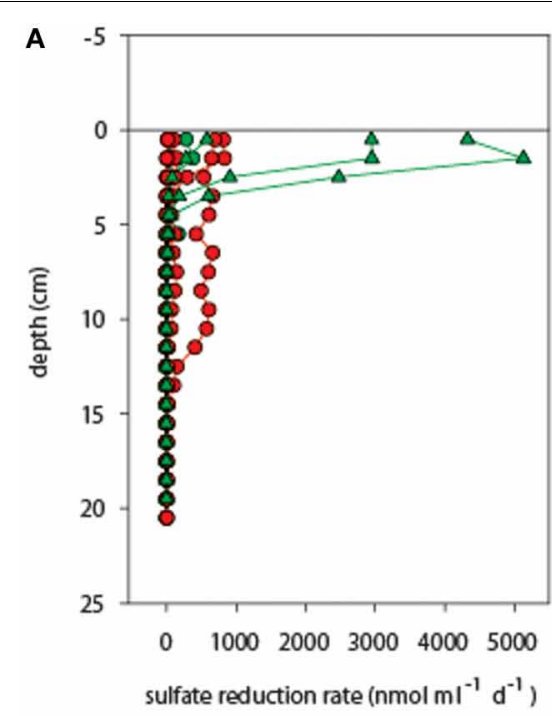

C

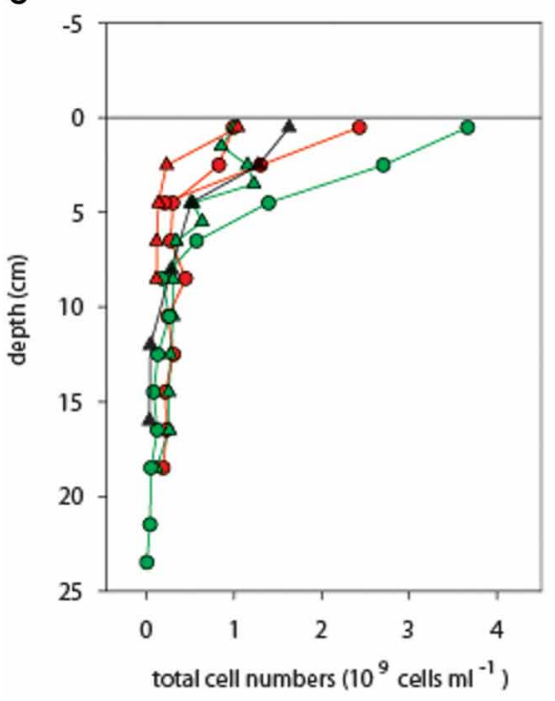

FIGURE 3 | Activity and biomass of microbial communities associated with different temperature ranges. (A) Potential sulfate reduction rates and (B) sulfate concentrations were determined in adjacent cores (not available for cold cores). Total single cells (C) and OTU numbers (D) generally decreased with increasing sediment depth [the lines in (D) indicate average

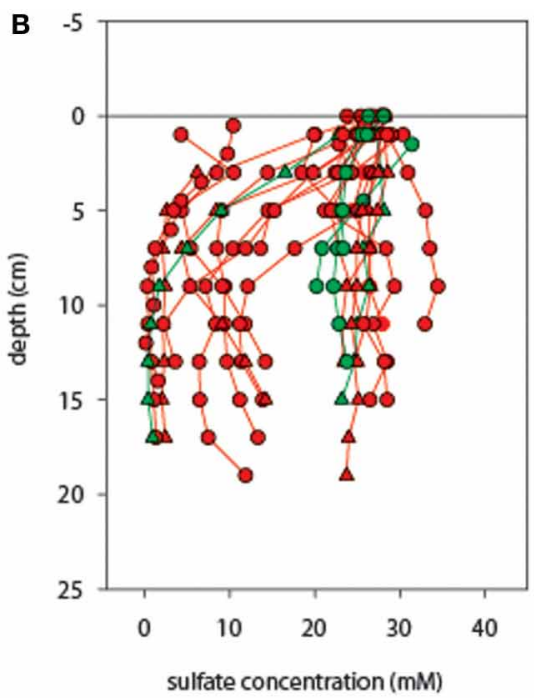

D

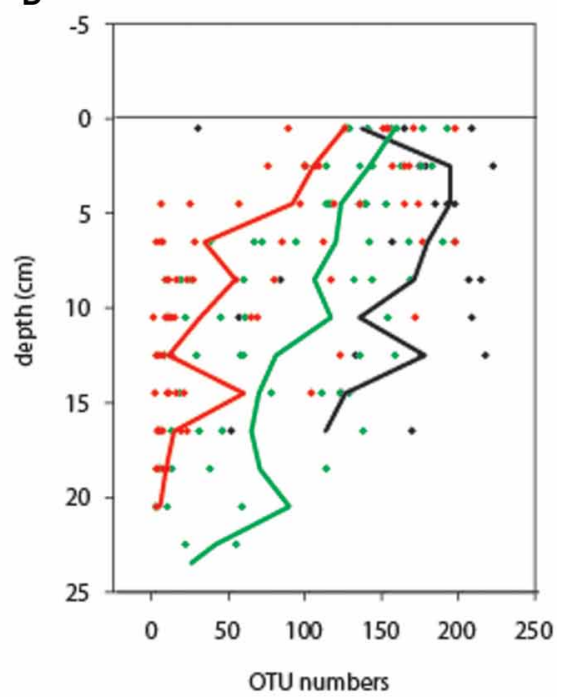

OTU numbers across cores]. Temperature categories indicated by color codes are cold $\left(T<10^{\circ} \mathrm{C}\right.$, black symbols), medium $\left(10^{\circ} \mathrm{C} \leq T<40^{\circ} \mathrm{C}\right.$, green symbols), and hot ( $T \geq 40^{\circ} \mathrm{C}$, red symbols), as measured in the upper $10 \mathrm{~cm}$ of sediment before coring. Circles and triangles correspond to mat-covered and mat-free sediments, respectively.

Guaymas Basin sediments are long known to be an interesting natural laboratory for the study of temperature-dependent oxidation of methane and sulfate reduction, and both processes have been found over a wide range of temperatures (Weber and Jørgensen, 2002; Kallmeyer and Boetius, 2004; Holler et al., 2011; Biddle et al., 2012). In general, at $20^{\circ} \mathrm{C}$ potential microbial sulfate reduction was strongly repressed below 4-5 cm (Figure 3A), despite the presence of sulfate and methane as well as other electron donors throughout the core, a phenomenon previously observed for Guaymas Basin sediments (Martens, 1990; Elsgaard et al., 1994; Weber and Jørgensen, 2002; Dhillon et al., 2005; Biddle et al., 2012; McKay et al., 2012).

Potentially, episodic heat pulses by upward advecting hot fluids may act as strong disturbances to the microbial assemblages 


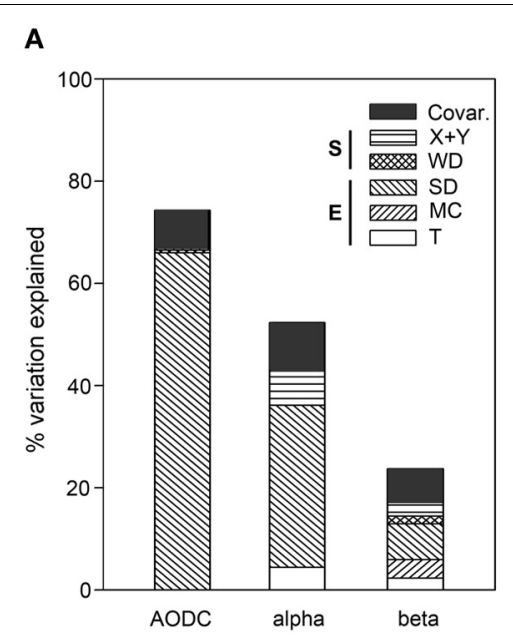

FIGURE 4 | (A) Partitioning of the variation in total cell numbers (AODC), bacterial OTU numbers (alpha-diversity) and ARISA bacterial community structure (beta-diversity) as a function of environmental and spatial parameters. The plot depicts the percent explained variation by each significant contextual parameter. Environmental variables (E) included $T$

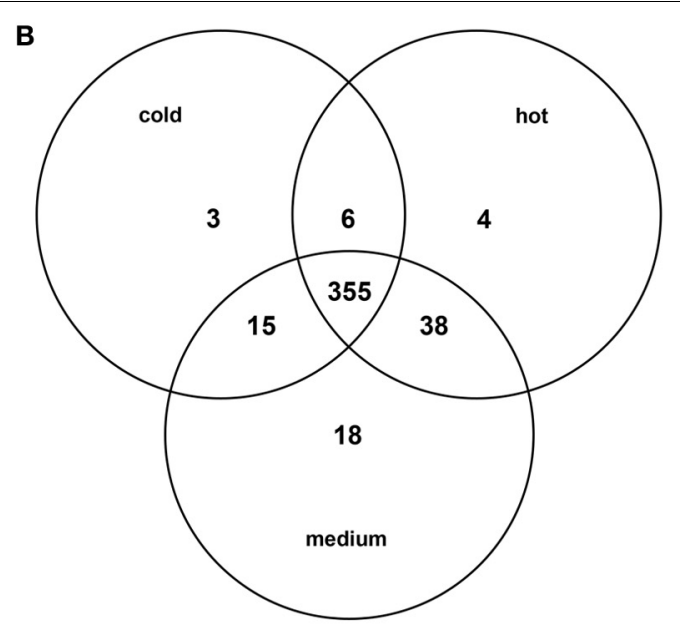

(subsurface temperature), MC (mat presence/color) and SD (sediment depth). Spatial variables (S) included WD (water depth) as well as $X+Y$ (spatial distance). (B) OTU partitioning according to the three temperature categories, namely cold $\left(T<10^{\circ} \mathrm{C}\right)$, medium $\left(10^{\circ} \mathrm{C} \leq T<40^{\circ} \mathrm{C}\right)$ and hot $\left(T \geq 40^{\circ} \mathrm{C}\right)$, with $T$ measured in the upper $10 \mathrm{~cm}$ of sediment.

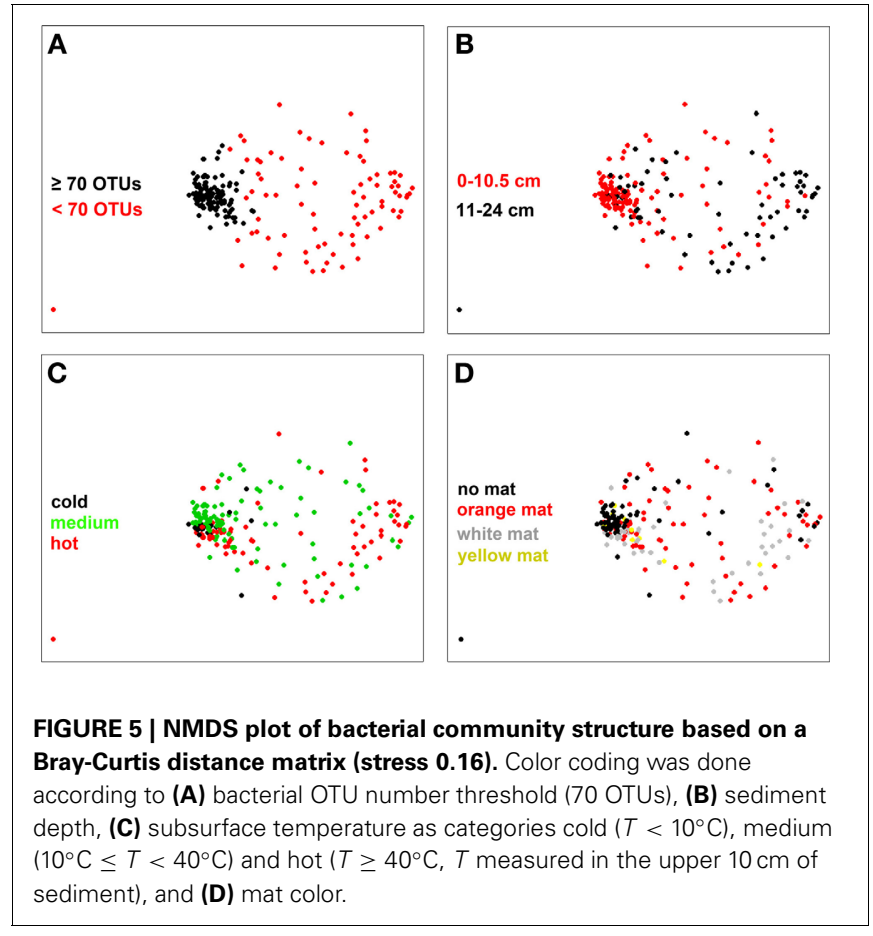

selected by certain temperature ranges in space and time. Upward advection of very hot fluids $>100^{\circ} \mathrm{C}$ could even lead to sterilization of the present assemblages, which then will be repopulated by the surface communities. This may explain the reduction or disappearance of biomass and diversity below $5-10 \mathrm{~cm}$ sediment depth detected in total cell numbers (Figure 3C), as well as bacterial OTU numbers (Figure S3). A substantial decline in cell numbers within a decimeter of the seafloor has also been observed in other highly fluid-flow advected marine sediments (Lösekann et al., 2007; Grünke et al., 2011), as well as in disturbed seep environments such as submarine mud volcanoes (Pop Ristova et al., 2012). If such geophysical disturbances can affect microbial abundances, they are also likely to affect community diversity and function. Even though archaeal diversity was not covered by our molecular approach, it is known for instance that archaea isolated from Guaymas Basin have demonstrated susceptibility to heavy metals (Edgcomb et al., 2004) or to the combination of low $\mathrm{pH}$, high sulfide and low temperature typically present in vent fluids (Lloyd et al., 2005).

The rapid loss of OTU number and microbial activity with sediment depth and increasing temperature indicate that from a relatively diverse community, only few members can occupy the niches available in the deep hot sediments at Guaymas (Figures 3-5). Interestingly, most of these OTUs were not unique, but occurred throughout the surface sediments sampled from the vent field. Hence, it seems likely that the prevailing diverse communities of bacteria in the highly reduced surface sediments of Guaymas Basin are functioning as a seed bank to deeper depths, and that many community members are adapted to a relatively wide range of temperature conditions. This is in general accordance with findings on the relatively broad temperature ranges of anaerobic methane oxidizers and sulfate reducers at Guaymas (Elsgaard et al., 1994; Weber and Jørgensen, 2002; Kallmeyer and Boetius, 2004; Holler et al., 2011; Biddle et al., 2012). Furthermore, ANME1-Guaymas archaea were previously found at temperatures between 20 and $>90^{\circ} \mathrm{C}$, suggesting their eurythermal nature and adaptation to fluctuations in temperature and heat flow (Biddle et al., 2012). Most likely the small-scale variation in space and time of the upward advective transport of hot hydrothermal fluids, and downward mixing of seawater penetrating surficial sediments (Gundersen et al., 1992) is likely exerting a substantial challenge to the microbial community, leading to substantial losses in diversity with sediment depth, and blurring a 
typical temperature-induced zonation of microbial habitats in the sediments.

\section{OTHER NICHE EFFECTS ON BACTERIAL COMMUNITY COMPOSITION}

Beggiatoa mats are generally linked to steep gradients and high fluxes of sulfide, DIC and $\mathrm{CH}_{4}$; they can be flushed by oxygenated seawater (Gundersen et al., 1992) and indicate hotspots of $\mathrm{CH}_{4}$ and sulfur cycling (Lichtschlag et al., 2010; Lloyd et al., 2010; Grünke et al., 2012; McKay et al., 2012). Their distribution across the investigated area at Guaymas Basin was patchy and not directly related to bathymetry or temperature regimes. Thus, we investigated whether the sampled areas may represent hotspots of bacterial diversity, especially via the presence of Beggiatoa that have been proposed to be acting as ecosystem engineers at Guaymas Basin by "providing specialized habitats for unique assemblages of species, thereby creating seafloor biodiversity hotspots" (Levin and Dayton, 2009). OTU number was compared across different mat types and mat-free sediments. In the top $2.5 \mathrm{~cm}$ sediment layers, mat-covered sediments were associated on average with fewer OTU with 137 OTU $(n=30)$ as compared to 162 OTU $(n=14)$ in mat-free sediments (twosample Wilcoxon test, $W=115, P=0.0172$ ). These numbers are comparable to those found in and around sulfide-oxidizer mats at cold seeps along the Norwegian continental margin (on average 121-166 OTUs in $0-2.5 \mathrm{~cm}$ sediment depth; Grünke et al., 2012). The total OTU number of 439 detected in Guaymas Basin sediments was similar to bacterial OTUs from a cold seep site at the West African margin ( 3200 m water depth, 450 OTUs; Pop Ristova et al., 2012). The percentage of shared OTUs between mat-covered and mat-free sediments $(63-88 \%, 0-24 \mathrm{~cm})$ was slightly higher than what has previously been found in a study on bacterial sulfide oxidizer mats at the Norwegian margin (41-63\%, 0-2.5 cm; Grünke et al., 2012), and for other chemosynthetic communities at the cold seep REGAB of the West African margin (average 74\%, 0-10 cm; Pop Ristova et al., 2012). The effects on community diversity of mat presence and color (corresponding to different Beggiatoa spp.) (McKay et al., 2012), could not be further disentangled in this study, because of the highly variable temperature regimes within the different mats. Although mat-forming sulfide oxidizers of the family Beggiatoaceae have previously been shown to specifically associate with certain types of bacteria (Kojima et al., 2006; Prokopenko et al., 2006; Teske et al., 2009), our results overall did not support the idea that the presence Beggiatoa mats was associated with higher bacterial diversity or specificity as compared to neighboring mat-free sediment communities.

\section{SPATIAL EFFECTS ON BACTERIAL COMMUNITIES}

The investigated hydrothermal field at Guaymas Basin was characterized by various structures typical for vent fields such as chimneys and mounds overgrown with Beggiatoa mats (Figure 2A), and dense Beggiatoa mats covering surface sediments (Figures 2B,C; Jannasch et al., 1989), vent chimneys and sulfide spires (Figures 2D-F). There was a slightly elevated area in the middle of the investigated area, where the water depth reached only $1995 \mathrm{~m}$ as compared to $>2000 \mathrm{~m}$ in the other areas, however, this feature was not distinctly related to a temperature gradient. Nevertheless, we explored whether spatial distance and bathymetry (mounds vs. troughs on the landscape level) had an effect on community assemblage.

The complex interplay of environmental and spatial factors on microbial diversity has already been observed in patchy terrestrial environments (e.g., Ramette and Tiedje, 2007b). Our analyses of $0.05 \mathrm{~km}^{2}$ of the Guaymas hydrothermal field showed that most tested biological variables, i.e., total cell numbers, OTU numbers and beta-diversity, were significantly influenced by spatial factors (X, Y or WD) at the scale of meters to hundreds of meters (Figure 4A). Total cell numbers were positively correlated with bathymetry, so that elevated landscape features showed a lower microbial biomass (based on partial linear regression models), but they were not correlated with latitude and longitude. OTU numbers were correlated to the geographic positions of the samples (both increasing with $\mathrm{Y}$ and decreasing with $\mathrm{X}$ ), but not to the bathymetric features. Changes in overall bacterial community structure could be related to changes in both bathymetry and geographic locations, yet we were unable to determine which environmental variables were explaining these spatial community patterns.

By comparing the effects of each investigated parameter, environmental factors ( $\mathrm{T}, \mathrm{SD}, \mathrm{MC}$ ) always explained more of biological variation than combined spatial variables $(\mathrm{X}, \mathrm{Y}, \mathrm{WD})$, in total cell numbers, OTU number, and beta-diversity. This is consistent with a recently published review on the current knowledge about what processes influence the distribution of microbes, and the percentages of total explained variation in our study are comparable to the overall reported mean of $50 \%$ across studies (Hanson et al., 2012). It should be noted that, because not all selective environmental variables can be assessed in field studies, and especially their past temporal variation remains unknown, pure spatial effects on community structure may be potentially overestimated (Cottenie, 2005; Hanson et al., 2012). Interpreted within a metacommunity ecology framework (Leibold et al., 2004), our findings overall suggest that Guaymas bacterial communities are subjected to a combination of species sorting (i.e., to dispersal associated with niche differentiation) and of mass effect (i.e., dispersal effects through source-sink relationships).

\section{CONCLUSION}

Guaymas Basin hydrothermal sediment bacterial communities displayed a high variation in community richness and activity on small spatial scales. Community activity, abundance and richness declined substantially with increasing temperature, indicating that only few microbial types of the core community of the investigated vent field were adapted to populate deep hot sediments at temperatures $>10^{\circ} \mathrm{C}$ and higher (Figure S7). However, community similarity was high across the different temperature regimes and habitat types sampled, and across the entire range of temperature regimes-from normal deep-sea settings to the predicted limits of life $>120^{\circ} \mathrm{C}$-only few unique microbial types were detected. This is best explained by the scenario of connected bacterial habitats, where temporary disturbances by the upward expulsion of hot fluids can locally decrease cell activity, biomass and diversity, and where a repopulation occurs by a diverse, eurythermic and more stable surface community of the highly 
reduced Guaymas sediments. Besides temperature and sediment depth, the presence of microbial mats, local bathymetry and spatial orientation in the vent field also showed significant effects on community richness and composition, but due to the complexity of the vent field, no distinct spatial gradient was detected, indicative of active but chaotic upward venting in space and time. Bacterial habitats seemed highly interconnected across the investigated vent area, which may be a consequence of dynamically fluctuating temperatures and biogeochemical factors.

\section{ACKNOWLEDGMENTS}

For their excellent support at sea we would like to thank the scientific team and crews of R/V Atlantis (Expedition AT15-40) and the Alvin submersible (operated by Woods Hole Oceanographic

\section{REFERENCES}

Baker, B. J., Lesniewski, R. A., and Dick, G. J. (2012). Genome-enabled transcriptomics reveals archaeal populations that drive nitrification in a deep-sea hydrothermal plume. ISME J. 6, 2269-2279. doi: 10.1038/ismej.2012.64

Bazylinski, D. A., Farrington, J. W., and Jannasch, H. W. (1988). Hydrocarbons in surface sediments from a Guaymas Basin hydrothermal vent site. Org. Geochem. 12, 547-558. doi: 10.1016/0146-6380(88)90146-5

Biddle, J. F., Cardman, Z., Mendlovitz, H., Albert, D. B., Lloyd, K. G., Boetius, A., et al. (2012). Anaerobic oxidation of methane at different temperature regimes in Guaymas Basin hydrothermal sediments. ISME J. 6, 1018-1031. doi: 10.1038/ismej.2011.164

Boetius, A., and Lochte, K. (1996). Effect of organic enrichments on hydrolytic potentials and growth of bacteria in deep-sea sediments. Mar. Ecol. Prog. Ser. 140, 239-250. doi: 10.3354/meps140239

Borcard, D., Legendre, P., and Drapeau, P. (1992). Partialling out the spatial component of ecological variation. Ecology 73, 1045-1055. doi: $10.2307 / 1940179$

Bowles, M. W., Nigro, L. M., Teske, A. P., and Joye, S. B. (2012). Denitrification and environmental factors influencing nitrate removal in Guaymas Basin hydrothermally altered sediments. Front. Microbiol. 3:377. doi: 10.3389/fmicb.2012.00377

Brown, M. V., Schwalbach, M. S., Hewson, I., and Fuhrman, J. A. (2005). Coupling 16S-ITS rDNA clone libraries and automated ribosomal intergenic spacer analysis to show marine microbial diversity: development and application to a time series. Environ. Microbiol.
7, 1466-1479. doi: 10.1111/j.14622920.2005.00835.x

Cardinale, M., Brusetti, L., Quatrini, P., Borin, S., Puglia, A. M., Rizzi, A., et al. (2004). Comparison of different primer sets for use in automated ribosomal intergenic spacer analysis of complex bacterial communities. Appl. Environ. Microbiol. 70, 6147-6156. doi: 10.1128/AEM.70.10.61476156.2004

Cottenie, K. (2005). Integrating environmental and spatial processes in ecological community dynamics. Ecol. Lett. 8, 1175-1182. doi: $\quad$ 10.1111/j.1461-0248.2005. 00820.x

Dhillon, A., Lever, M., Lloyd, K. G., Albert, D. B., Sogin, M. L., and Teske, A. (2005). Methanogen diversity evidenced by molecular characterization of Methyl Coenzyme M Reductase A ( $m c r A$ ) genes in hydrothermal sediments of the Guaymas Basin. Appl. Environ. Microbiol. 71, 4592-4601. doi: 10.1128/AEM.71.8.4592-4601.2005

Dhillon, A., Teske, A., Dillon, J., Stahl, D. A., and Sogin, M. L. (2003). Molecular characterization of sulfate-reducing bacteria in the Guaymas Basin. Appl. Environ. Microbiol. 69, 2765-2772. doi: 10.1128/AEM.69.5.2765-2772.2003

Edgcomb, V. P., Kysela, D. T., Teske, A., Gomez, A. D. V., and Sogin, M. L. (2002). Benthic eukaryotic diversity in the Guaymas Basin hydrothermal vent environment. Proc. Natl. Acad. Sci. U.S.A. 99, 7658-7662. doi: 10.1073/pnas.062186399

Edgcomb, V. P., Molyneaux, S. J., Saito, M. A., Lloyd, K., Böer, S., Wirsen, C. O., et al. (2004). Sulfide ameliorates metal toxicity for deep-sea hydrothermal vent Archaea. Appl. Environ. Microbiol. 70, 2551-2555. doi: 10.1128/AEM.70.4.2551-2555.2004

Institution, Woods Hole, MA). We thank Barbara MacGregor for meticulous record keeping on Guaymas sediment cores. Further, we acknowledge the help by Susanne Menger, Rafael Stiens, Daniel Santillano, Erika Weiz and Janine Felden during sampling as well as subsequent analyses. This study has been funded by NSF (Biological Oceanography grant OCE 0647633), as well as by the Leibniz program of the DFG to Antje Boetius, the MARUM Excellence Cluster and the Max Planck Society.

\section{SUPPLEMENTARY MATERIAL}

The Supplementary Material for this article can be found online at: http://www.frontiersin.org/Extreme_Microbiology/ 10.3389/fmicb.2013.00207/abstract

Elsgaard, L., Isaksen, M. F., Jørgensen, B. B., Alayse, A. M., and Jannasch, H. W. (1994). Microbial sulfate reduction in deep-sea sediments at the Guaymas Basin hydrothermal vent area: influence of temperature and substrates. Geochim. Cosmochim. Acta 58, 3335-3343. doi: 10.1016/0016-7037(94)90089-2

Felden, J., Wenzhöfer, F., Feseker, T., and Boetius, A. (2010). Transport and consumption of oxygen and methane in different habitats of the Håkon Mosby Mud Volcano (HMMV). Limnol. Oceanogr. 55, 2366-2380. doi: 10.4319/lo.2010.55.6.2366

Fuhrman, J. A., Steele, J. A., Hewson, I., Schwalbach, M. S., Brown, M. V., Green, J. L., et al. (2008). A latitudinal diversity gradient in planktonic marine bacteria. Proc. Natl. Acad. Sci. U.S.A. 105, 7774-7778. doi: 10.1073/pnas.0803070105

Grünke, S., Felden, J., Lichtschlag, A., Girnth, A.-C., De Beer, D., Wenzhöfer, F., et al. (2011). Niche differentiation among matforming, sulfide-oxidizing bacteria at cold seeps of the Nile Deep Sea Fan (Eastern Mediterranean Sea). Geobiology 9, 330-348. doi: 10.1111/j.1472-4669.2011.00281.x

Grünke, S., Lichtschlag, A., De Beer, D., Felden, J., Salman, V., Ramette, A., et al. (2012). Mats of psychrophilic thiotrophic bacteria associated with cold seeps of the Barents Sea. Biogeosciences 9, 2947-2960. doi: 10.5194/bg-9-2947-2012

Guezennec, J. G., Dussauze, J., Bian, M., Rocchiccioli, F., Ringelberg, D., Hedrick, D. B., et al. (1996). Bacterial community structure in sediments from Guaymas basin, Gulf of California, as determined by analysis of phospholipid ester-linked fatty acids. J. Mar. Biotechnol. 4, 165-175.
Gundersen, J. K., Jørgensen, B. B., Larsen, E., and Jannasch, H. W. (1992). Mats of giant sulphur bacteria on deep-sea sediments due to fluctuating hydrothermal flow. Nature 360, 454-456. doi: $10.1038 / 360454 \mathrm{a} 0$

Hanson, C. A., Fuhrman, J. A., HornerDevine, M. C., and Martiny, J. B. H. (2012). Beyond biogeographic patterns: processes shaping the microbial landscape. Nat. Rev. Microbiol. 10, 497-506.

Holler, T., Widdel, F., Knittel, K., Amann, R., Kellermann, M. Y., Hinrichs, K.-U., et al. (2011). Thermophilic anaerobic oxidation of methane by marine microbial consortia. ISME J. 5, 1946-1956. doi: 10.1038/ismej.2011.77

Hughes Martiny, J. B., Bohannan, B. J. M., Brown, J. H., Colwell, R. K., Fuhrman, J. A., Green, J. L., et al. (2006). Microbial biogeography: putting microorganisms on the map. Nat. Rev. Microbiol. 4, 102-112. doi: 10.1038/nrmicrol341

Jannasch, H. W., Nelson, D. C., and Wirsen, C. O. (1989). Massive natural occurrence of unusually large bacteria (Beggiatoa sp.) at a hydrothermal deep-sea vent site. Nature 342, 834-836. doi: $10.1038 / 342834 \mathrm{a} 0$

Jørgensen, B. B. (1978). A comparison of methods for the quantification of bacterial sulfate reduction in coastal marine sediments. Geomicrobiol. J. 1, 29-47. doi: 10.1080/01490457809377722

Kallmeyer, J., and Boetius, A. (2004). Effects of temperature and pressure on sulfate reduction and anaerobic oxidation of methane in hydrothermal sediments of Guaymas Basin. Appl. Environ. Microbiol. 70, 1231-1233. doi 10.1128/AEM.70.2.1231-1233.2004

Kallmeyer, J., Ferdelman, T. G., Weber, A., Fossing, H., and Jørgensen, 
B. B. (2004). A cold chromium distillation procedure for radiolabeled sulfide applied to sulfate reduction measurements. Limnol. Oceanogr. Meth. 2, 171-180. doi: 10.4319/lom.2004.2.171

Kojima, H., Koizumi, Y., and Fukui, M. (2006). Community structure of bacteria associated with sheaths of freshwater and brackish Thioploca species. Microb. Ecol. 52, 765-773. doi: $10.1007 / \mathrm{s} 00248-006-9127-8$

Kysela, D. T., Palacios, C., and Sogin, M. L. (2005). Serial analysis of V6 ribosomal sequence tags (SARST-V6): a method for efficient, high-throughput analysis of microbial community composition. Environ. Microbiol. 7, 356-364. doi: 10.1111/j.1462-2920.2004.00712.x

Legendre, P., and Legendre, L. (1998). Numerical Ecology. Amsterdam: Elsevier Science BV.

Leibold, M. A., Holyoak, M., Mouquet, N., Amarasekare, P., Chase, J. M., Hoopes, M. F., et al. (2004). The metacommunity concept: a framework for multi-scale community ecology. Ecol. Lett. 7, 601-613. doi: 10.1111/j.1461-0248.2004.00608.x

Levin, L. A., and Dayton, P. K. (2009). Ecological theory and continental margins: where shallow meets deep. Trends Ecol. Evol. 24, 606-617. doi: 10.1016/j.tree.2009.04.012

Lichtschlag, A., Felden, J., Brüchert, V., Boetius, A., and De Beer, D. (2010). Geochemical processes and chemosynthetic primary production in different thiotrophic mats of the Håkon Mosby mud volcano (Barents Sea). Limnol. Oceanogr. 55, 931-949. doi: 10.4319/lo.2009.55.2.0931

Lloyd, K. G., Albert, D. B., Biddle, J. F., Chanton, J. P., Pizarro, O., and Teske, A. (2010). Spatial structure and activity of sedimentary microbial communities underlying a Beggiatoa spp. mat in a Gulf of Mexico hydrocarbon seep. PLoS ONE 5:e8738. doi: 10.1371/journal.pone. 0008738

Lloyd, K. G., Edgcomb, V. P., Molyneaux, S. J., Böer, S., Wirsen, C. O., Atkins, M. S., et al. (2005). Effect of dissolved sulfide, $\mathrm{pH}$, and temperature on the growth and survival of marine hyperthermophilic archaea. Appl. Environ. Microbiol. 71, 6383-6387. doi: 10.1128/AEM.71.10.63836387.2005

Lösekann, T., Knittel, K., Nadalig, T., Fuchs, B., Niemann, H., Boetius, A., et al. (2007). Diversity and abundance of aerobic and anaerobic methane oxidizers at the
Haakon Mosby Mud Volcano, Barents Sea. Appl. Environ. Microbiol. 73, 3348-3362. doi: 10.1128/AEM.00016-07

Martens, C. S. (1990). Generation of short chain acid anions in hydrothermally altered sediments of the Guaymas Basin, Gulf of California. Appl. Geochem. 5, 71-76. doi: 10.1016/0883-2927(90) 90037-6

McKay, L. J., MacGregor, B. J., Biddle, J. F., Albert, D. B., Mendlovitz, H. P., Hoer, D. R., et al. (2012). Spatial heterogeneity and underlying geochemistry of phylogenetically diverse orange and white Beggiatoa mats in Guaymas Basin hydrothermal sediments. DeepSea Res. Part I 67, 21-31. doi 10.1016/j.dsr.2012.04.011

Mével, G., Faidy, C., and Prieur, D. (1996). Distribution, activity, and diversity of heterotrophic nitrifiers originating from East Pacific deep-sea hydrothermal vents. Can. J. Microbiol. 42, 162-171. doi: 10.1139/m96-024

Meyer-Reil, L.-A. (1983). Benthic response to sedimentation events during autumn to spring at a shallow water station in the Western Kiel Bight. Mar. Biol. 77, 247-256. doi: 10.1007/BF00395813

Nelson, D. C., Wirsen, C. O., and Jannasch, H. W. (1989). Characterization of large, autotrophic Beggiatoa spp. abundant at hydrothermal vents of the Guaymas Basin. Appl. Environ. Microbiol. 55, 2909-2917.

Nocker, A., Burr, M., and Camper, A. K. (2007). Genotypic microbial community profiling: aA critical technical review. Microb. Ecol. 54, 276-289. doi: 10.1007/s00248006-9199-5

Paull, C. K., Ussler Iii, W., Peltzer, E. T., Brewer, P. G., Keaten, R., Mitts, P. J., et al. (2007). Authigenic carbon entombed in methane-soaked sediments from the northeastern transform margin of the Guaymas Basin, Gulf of California. Deep-Sea Res. Part II 54, 1240-1267. doi: 10.1016/j.dsr2.2007.04.009

Pop Ristova, P., Wenzhöfer, F., Ramette, A., Zabel, M., Fischer, D., Kasten, S., et al. (2012). Bacterial diversity and biogeochemistry of different chemosynthetic habitats of the REGAB cold seep (West African margin, $3160 \mathrm{~m}$ water depth) Biogeosciences 9, 5031-5048. doi: 10.5194/bg-9-5031-2012

Prokopenko, M. G., Hammond, D. E., Berelson, W. M., Bernhard, J. M., Stott, L., and Douglas, R.
(2006). Nitrogen cycling in the sediments of Santa Barbara basin and Eastern Subtropical North Pacific: nitrogen isotopes, diagenesis and possible chemosymbiosis between two lithotrophs (Thioploca and Anammox) - "riding on a glider." Earth Planet. Sci. Lett. 242, 186-204. doi: 10.1016/j.epsl.2005.11.044

Ramette, A. (2007). Multivariate analysis in microbial ecology. FEMS Microbiol. Ecol. 62, 142-160. doi 10.1111/j.1574-6941.2007.00375.x

Ramette, A. (2009). Quantitative community fingerprinting methods for estimating the abundance of operational taxonomic units in natural microbial communities. Appl. Environ. Microbiol. 75, 2495-2505. doi: 10.1128/AEM.02409-08

Ramette, A., and Tiedje, J. M. (2007a), Biogeography: an emerging cornerstone for understanding prokaryotic diversity, ecology, and evolution. Microb. Ecol. 53, 197-207. doi: 10.1007/s00248-005-5010-2

Ramette, A., and Tiedje, J. M. (2007b). Multiscale responses of microbial life to spatial distance and environmental heterogeneity in a patchy ecosystem. Proc. Natl. Acad. Sci. U.S.A. 104, 2761-2766. doi: 10.1073/pnas.0610671104

Simoneit, B. R. T., and Lonsdale, P. F. (1982). Hydrothermal petroleum in mineralized mounds at the seabed of Guaymas Basin. Nature 295, 198-202. doi: 10.1038/295198a0

Teske, A. (2010). "Sulfate-reducing and methanogenic hydrocarbonoxidizing microbial communities in the marine environment," in Handbook of Hydrocarbon and Lipid Microbiology, Part 21, ed K. N. Timmis (Berlin, Heidelberg: Springer), 2203-2223. doi 10.1007/978-3-540-77587-4_160

Teske, A., Dhillon, A., and Sogin, M. S. (2003). Genomic Markers of ancient anaerobic microbial pathways: sulfate reduction, methanogenesis, and methane oxidation. Biol. Bull. 204, 186-191. doi: 10.2307/ 1543556

Teske, A., Hinrichs, K.-U., Edgcomb, V., Gomez, A. D. V., Kysela, D., Sylva, S. P., et al. (2002). Microbial diversity of hydrothermal sediments in the Guaymas Basin: evidence for anaerobic methanotrophic communities. Appl. Environ. Microbiol. 68, 1994-2007. doi 10.1128/AEM.68.4.1994-2007.2002

Teske, A., Jørgensen, B. B., and Gallardo, V. A. (2009). Filamentous bacteria inhabiting the sheaths of marine Thioploca spp. on the Chilean continental shelf. FEMS
Microbiol. Ecol. 68, 164-172. doi: 10.1111/j.1574-6941.2009.00659.x

Van Gaever, S., Moodley, L., De Beer, D., and Vanreusel, A. (2006). Meiobenthos at the arctic Håkon Mosby Mud Volcano, with a parental-caring nematode thriving in sulfide-rich sediments. Mar. Ecol. Prog. Ser. 321, 143-155. doi: 10.3354/meps321143

Von Damm, K. L., Edmond, J. M. Measures, C. I., and Grant, B. (1985). Chemistry of submarine hydrothermal solutions at Guaymas Basin, Gulf of California. Geochim. Cosmochim. Acta 49, 2221-2237. doi: 10.1016/0016-7037(85)90223-6

Weber, A., and Jørgensen, B. B. (2002). Bacterial sulfate reduction in hydrothermal sediments of the Guaymas Basin, Gulf of California, Mexico. Deep-Sea Res. Part I 49, 827-841. doi: 10.1016/S0967-0637(01)00079-6

Welhan, J. A., and Lupton, J. E. (1987). Light hydrocarbon gases in Guaymas Basin hydrothermal fluids: thermogenic versus abiogenic origin. AAPG Bull 71, 215-223.

Zinger, L., Amaral-Zettler, L. A., Fuhrman, J. A., Horner-Devine, M. C., Huse, S. M., Welch, D. B. M., et al. (2011). Global patterns of bacterial beta-diversity in seafloor and seawater ecosystems. PLoS ONE 6:e24570. doi: 10.1371/journal.pone. 0024570

Conflict of Interest Statement: The authors declare that the research was conducted in the absence of any commercial or financial relationships that could be construed as a potential conflict of interest.

Received: 25 March 2013; accepted: 05 July 2013; published online: 25 July 2013. Citation: Meyer S, Wegener G, Lloyd KG, Teske A, Boetius A and Ramette A (2013) Microbial habitat connectivity across spatial scales and hydrothermal temperature gradients at Guaymas Basin. Front. Microbiol. 4:207. doi: 10.3389/ fmicb.2013.00207

This article was submitted to Frontiers in Extreme Microbiology, a specialty of Frontiers in Microbiology

Copyright (ㅇ 2013 Meyer, Wegener, Lloyd, Teske, Boetius and Ramette. This is an open-access article distributed under the terms of the Creative Commons Attribution License, which permits use, distribution and reproduction in other forums, provided the original authors and source are credited and subject to any copyright notices concerning any third-party graphics etc. 